\title{
Holistic Ship Design Optimization: Merchant and Naval Ships
}

Apostolos D. Papanikolaou ${ }^{1}$

\begin{abstract}
The present paper provides a brief introduction to a holistic approach to ship design optimization, defines the generic ship design optimization problem, and demonstrates its solution by using advanced optimization techniques for the computer-aided generation, exploration, and selection of optimal designs. It discusses proposed methods on the basis of some typical ship design optimization problems of cargo and naval ships related to multiple objectives, leading to improved and partly innovative design features with respect to ships' economy, cargo carrying capacity, safety, survivability, comfort, required powering, environmental protection, or combat strength, as applicable.
\end{abstract}

Key words: holistic ship design, parametric design, multi-criteria optimization, naval ships.

\section{Resumen}

Este documento brinda una breve introducción a un enfoque holistico a la optimización del diseño de embarcaciones, define el problema genérico de la optimización del diseño de embarcaciones y demuestra su solución mediante el uso de técnicas avanzadas de optimización asistidas por computador para la generación, exploración y selección de diseños óptimos. Discute los métodos propuestos sobre la base de algunos problemas típicos de optimización de diseño de embarcación de buques de carga y navales relacionados a los objetivos múltiples, conllevando a características de diseño mejoradas y parcialmente innovadoras con respecto a la economía de la embarcación, capacidad de carga, seguridad, supervivencia, comodidad, potencia requerida, protección ambiental o fortaleza de combate, como sea aplicable.

Palabras claves: diseño holístico de buques, diseño paramétrico, optimización de múltiples criterios, buques navales.

Date Received: December 7th, 2010 - Fecha de recepción: 7 de Diciembre de 2010

Date Accepted: January 21th, 2011 - Fecha de aceptación: 21 de Enero de 2011

${ }^{1}$ National Technical University of Athens, Ship Design Laboratory. Athens-Zografou, Greece. e-mail: papa@deslab.ntua.gr 


\section{Introduction}

Ships are built to cover needs of society through the provision of specific services. These services may be on a commercial or non-commercial basis; whereas, in the first case (commercial ships) the objective is to generate profit for the ship owner, the latter case is related to a public service of some kind, the cost of which is generally assumed by a governmental authority. The main bulk of commercial ships are cargo ships, which carry all types of cargo (solid and liquid cargo or passengers) and provide in fact the largest (by volume of cargo and transport distance, [ton-miles]) worldwide transportation work, compared to other modes of transport.

The design of ships is a complex endeavor requiring the successful coordination of many disciplines, of both technical and non-technical nature, and of individual experts to arrive at valuable design solutions. Inherently coupled with the design process is design optimization, namely the selection of the best solution out of many feasible ones on the basis of a criterion, or rather a set of criteria. Such evaluation criteria are the shipbuilding cost or the required freight rate for merchant ships or more complex ones that include, besides economy, ship performance in terms of safety, comfort, survivability in intact and damage condition and environmental friendliness. A systemic approach to ship design may consider the ship as a complex system integrating a variety of subsystems and their components, e.g., for merchant ships subsystems for cargo storage and handling, energy/power generation and ship propulsion, accommodation of crew/passengers and ship navigation, whereas for naval ships combat systems are added.

Considering that ship design should actually address the whole ship's life cycle, it may be split into various stages that are traditionally composed of the concept/preliminary design, the contractual and detailed design, the ship construction/fabrication process, and ship operation for an economic life and scrapping/recycling. It is evident that an optimal ship is the outcome of a holistic optimization of the entire, above defined, ship system over its whole life cycle. But even the simplest component of the above-defined optimization problem, namely the $1^{\text {st }}$ loop (conceptual/preliminary design), is complex enough to be simplified (reduced) in practice. Inherent to ship design optimization are the conflicting requirements resulting from the design constraints and optimization criteria (merit or objective functions), reflecting the competing interests of the various ship design stake holders (ship-owner, shipbuilder, cargo owner and cargo forwarder, flag and class authorities, etc.).

The present paper provides a brief introduction to a holistic approach to ship design optimization, defines the generic ship design optimization problem, and demonstrates its solution by use of advanced optimization techniques for the computer-aided generation, exploration, and selection of optimal designs. It discusses proposed methods on the basis of some typical ship design problems of cargo and naval ships related to optimizations with multiple objectives and leading to improved and partly innovative design features with respect to ship economy, cargo carrying capacity, safety, survivability, comfort, required powering, environmental protection or combat strength (naval ships), as applicable.

\section{Holistic Ship Design Optimization}

Inherently coupled with the design process is design optimization, namely the selection of the best solution out of many feasible ones on the basis of a criterion, or rather a set of criteria. A systemic approach to ship design may consider the ship as a complex system, integrating a variety of subsystems and their components, e.g., subsystems for cargo storage and handling, energy/power generation and ship propulsion, accommodation of crew/passengers, and ship navigation. They are all serving well-defined ship functions.

Ship functions may be divided into two main categories, namely payload functions and inherent ship functions.For example, for Ro-Ro passenger ships, the payload functions are all those related to the provision of public and private accommodation spaces for the passengers and spaces/handling and access equipment for the cargo (Ro-Ro decks, ramps, ventilation, etc.); inherent ship functions 
Fig. 1. Payload and Ship functions of Cargo Ships (Levander, 2003)

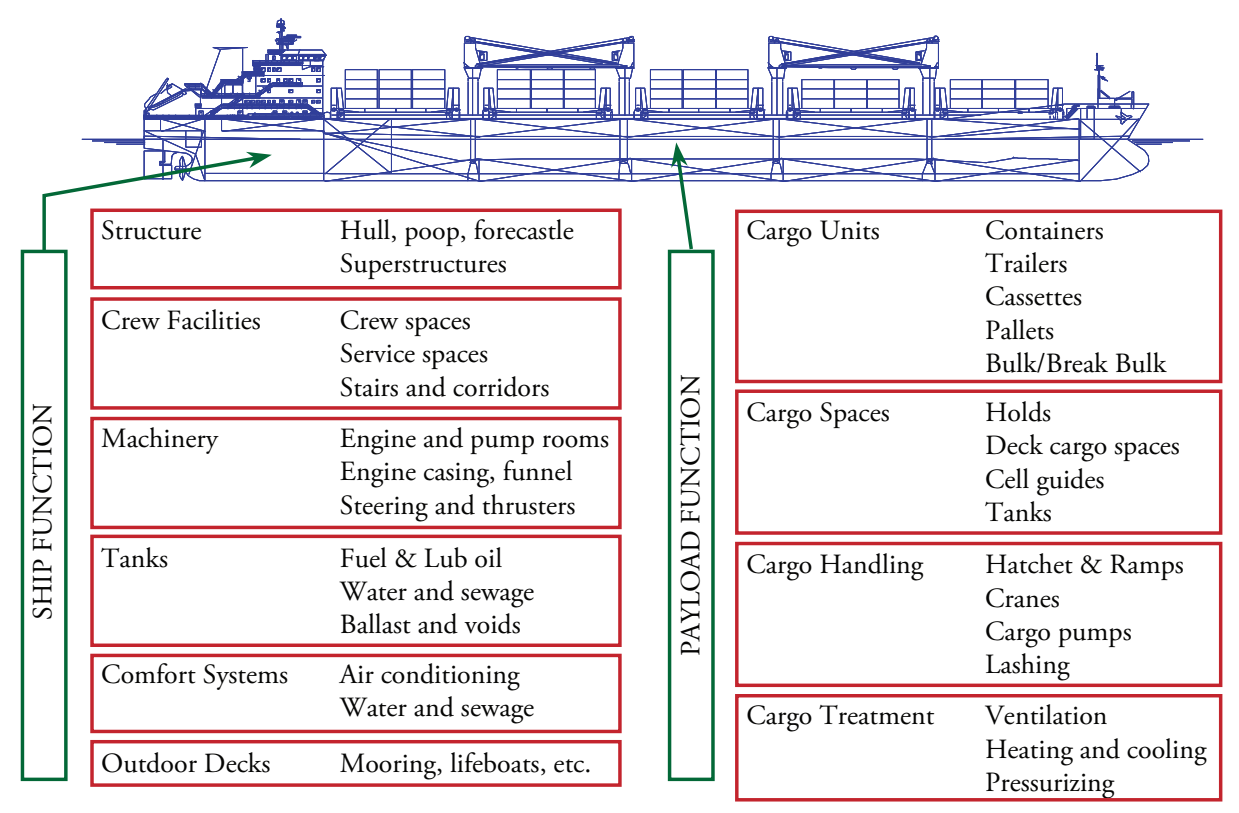

are those related to the transport of passengers and cargo safely from port to port with certain speed, namely the ship as a system, consisting of ship's hull (main and superstructure), facilities of crew, navigation control (bridge), machinery, tanks (fuel and lubrication oil, water and sewage, ballast and voids), comfort systems (air conditioning, water and sewage, electrical), mooring and life-saving equipment, etc. (Fig. 1).

Independently, considering that ship design should actually address the whole ship's life cycle, it may be split into various stages that are traditionally composed of the concept/preliminary design, the contractual and detailed design, the ship construction/fabrication process, and ship operation for an economic life and scrapping/ recycling. It is evident that the optimal ship with respect to her whole life cycle is the outcome of a holistic $^{1}$ optimization of the entire, above defined ship system for its life-cycle. It is noted that mathematically, every constituent of the above defined life-cycle ship system forms evidently itself a complex nonlinear optimization problem for the design variables, with a variety of constraints and criteria/objective functions to be jointly optimized. Even the simplest component of the ship design

1 Principle of holism according to Aristotle (Metaphysics): "The whole is more than the sum of the parts" process, namely the 1st loop (conceptual/ preliminary design), is complex enough to be simplified $\left(\right.$ reduced $\left.^{2}\right)$ in practice. Also, inherent to ship design optimization are the conflicting requirements resulting from the design constraints and optimization criteria (merit or objective functions), reflecting the interests of the various ship design stake holders: ship owners/operators, ship builders, classification society/coast guard, regulators, insurers, cargo owners/forwarders, port operators etc.

Assuming a specific set of requirements (usually the shipowner's requirements for merchant ships or mission statement for naval ships), a ship needs to be optimized for lowest construction cost, for highest operational efficiency or lowest Required Freight Rate (RFR), for highest safety and comfort of passengers/crew, for satisfactory protection of cargo and the ship herself as hardware and last but not least, for minimum environmental impact, particularly for oil carriers with respect to marine pollution in case of accidents and for high-speed vessels with respect to generated wave wash. Recently, even aspects of ship engine emissions

\footnotetext{
${ }^{2}$ Principle of reductionism may be seen as the opposite of holism, implying that a complex system can be approached by reduction to its fundamental parts. However, holism and reductionism should be regarded as complementary approaches, as they are both needed to satisfactorily address complex systems in practice.
} 
and air pollution need to be considered (see current discussions about the Energy Efficiency Design Index (EEDI), International Maritime Organization-MEPC, 2008). Many of these requirements are clearly conflicting and a decision regarding the optimal ship design needs to be rationally made.

To make things more complex but coming closer to reality, even the specification of a set of design requirements with respect to ship type, cargo capacity, speed, range, etc. is complex enough to require another optimization procedure that satisfactorily considers the interests of all shareholders of the ship as an industrial product and service vehicle of international markets or others. Actually, the initial set of ship design requirements is the outcome of a compromise of intensive discussions between highly experienced decision makers, mainly on the shipbuilder's side and end users who attempt to articulate their desires and tradeoffs they are willing to allow. A way to undertake and rationally consolidate this kind of discussion has been advanced by the EUfunded project LOGBASED (Brett et al., 2006).

Since the mid 60s with the advance of computer hard- and software more and more parts of the design process were taken over by computers, particularly the heavy algorithmic and drafting elements of ship design. Simultaneously, the first computer-aided preliminary design software systems were introduced, dealing with the mathematical parametric exploration of the design space on the basis of empirical/simplified ship models for specific ship types or the optimization of design variables for specific economic criteria by gradient based search techniques. With the further and faster advance of computer hard- and software tools, along with their integration into powerful hard- and software design systems, the time has come to look ahead in ship design optimization in a holistic way, namely by addressing and optimizing several and gradually all aspects of ship life (or all elements of the entire ship life-cycle system), at least the stages of design, construction and operation; within a holistic ship design optimization we should herein also understand exhaustive multi-objective and multi-constrained ship design optimization procedures even for individual stages of ship life (e.g., conceptual design) with least reduction of the entire real problem (Nowacki, 2009, Andrews et al., 2009, Papanikolaou et al., 2009a, and Papanikolaou, 2009b).

The use of Genetic Algorithms (GA), combined with gradient-based search techniques in micro-scale exploration and with a utility functions technique for the design evaluation, is advanced in the present paper as a generic-type optimization technique to generate and identify optimized designs through effective exploration of the large-scale, nonlinear design space and a multitude of evaluation criteria. Several applications of this generic, multi-objective ship design optimization approach by using the design software platform of the Ship Design Laboratory of NTUA, integrating well-established naval architectural and optimization software packages with various application methods and software tools, as necessary to evaluate stability, resistance, seakeeping, structural integrity, etc., may be found in the listed references. The following examples, deduced from past projects of NTUASDL, may be highlighted.

- Hydrodynamic hull form optimization of high-speed, twin-hull vessels (Papanikolaou, 1991, Papanikolaou et al., 1996).

- Hull form optimization of high-speed monoand twin-hull vessels for least wave resistance and wave wash (EU project FLOWMART, Zaraphonitis and Papanikolaou, 2003).

- Multi-objective optimization of naval ships (Boulougouris and Papanikolaou, 2004).

- Hull form optimization of a wave piercing, high-speed, mono-hull vessel for least resistance and best seakeeping (EU project VRSHIP-ROPAX2000, Boulougouris and Papanikolaou, 2006).

- Parametric design and multi-objective optimization of conventional and high-speed ROPAX ships (Zaraphonitis and Papanikolaou, 2003, Skoupas et al., 2009).

- Risk-based ship design (see a series of examples of application by various research teams, Papanikolaou (ed), 2009c).

- Logistics-based optimization of ship design (Gkohari and Papanikolaou, 2010). 
- Multi-objective tanker optimization (Papanikolaou et al., 2010).

\section{The Generic Ship Design Optimization Problem}

Within a holistic ship design optimization, we should herein mathematically understand exhaustive multi-objective and multi-constrained optimization procedures with least reduction of the entire real design problem. The generic ship design optimization problem and its basic elements may be defined as follows (Fig. 2).

- Optimisation Criteria (Merit Functions, Goals): This refers to a list of mathematically defined performance/efficiency indicators that may be eventually reduced to an economic criterion, namely the profit of the initial investment. Independently, there may be optimization criteria (merit functions or goals) that may be formulated without direct reference to economic indicators, see, e.g., optimization studies for a specific X ship function, like ship performance in calm water and in seaways, ship safety, ship strength including fatigue, etc. The ship design optimization criteria are generally complex nonlinear functions of the design parameters (vector of design variables) and are often defined by algorithmic routines in a computer-aided design procedure. According to Levander (2003), the most important performance indicators for cargo vessels are summarized in Fig. 3.

- Constraints: It mainly refers to a list of mathematically defined criteria (in the form of mathematical inequalities or equalities) resulting from regulatory frameworks pertaining to safety (for ships, mainly the international SOLAS and MARPOL regulations). This list may be extended by a second set of criteria characterized by uncertainty with respect to their actual values and being determined by the market conditions (demand and supply data for merchant ships), by the cost of major materials (for ships: cost of steel, fuel, workmanship), by the anticipated financial conditions (cost of money, interest rates), and other case-specific constraints. It should be noted that the latter set of criteria is often regarded as a set of input data with uncertainty to the optimization problem and may be assessed on the basis of probabilistic assessment models.

- Design Parameters: It refers to a list of parameters (vector of design variables)

Fig. 2. Generic Ship Design Optimization Problem

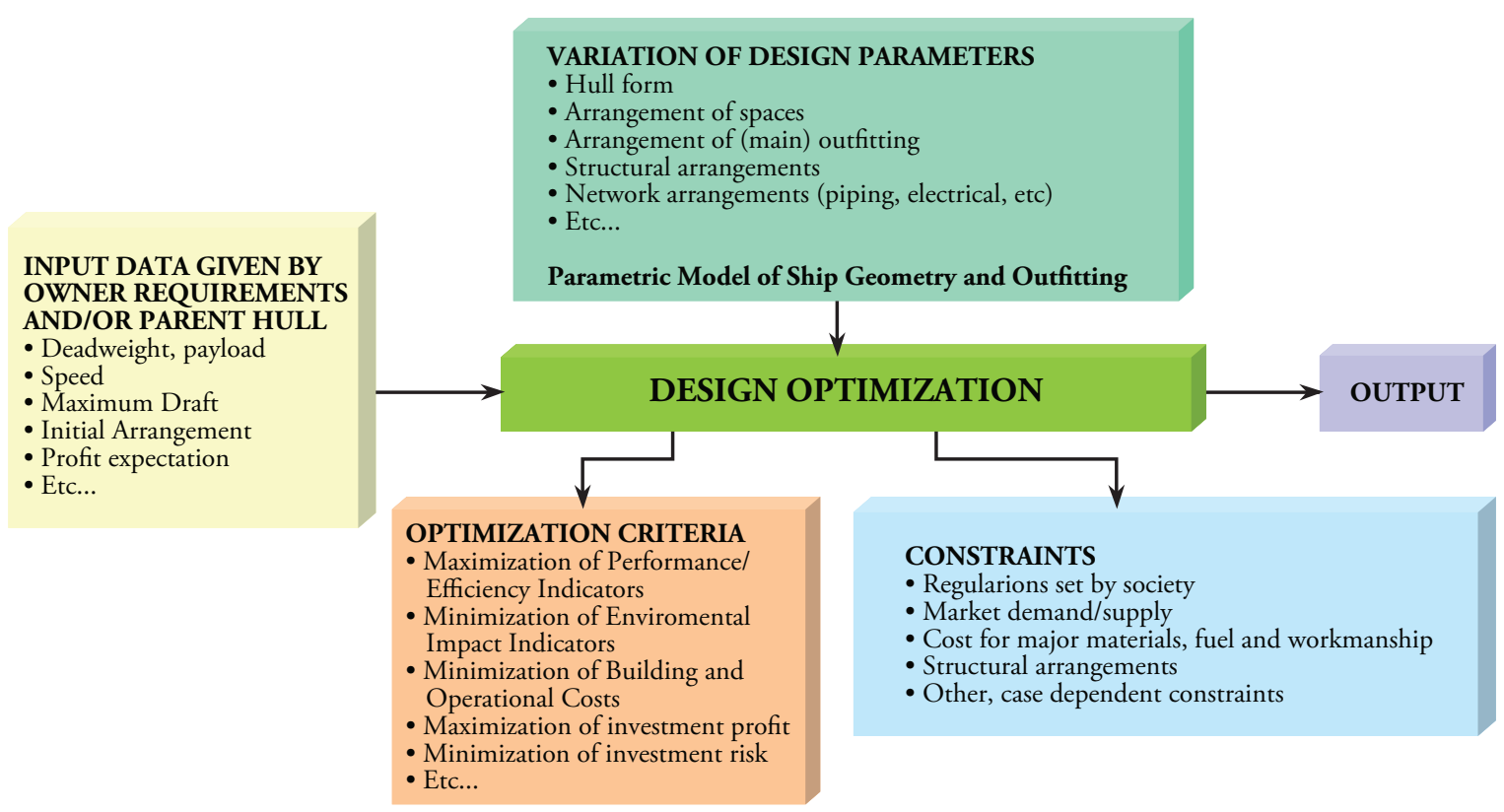


Fig. 3. Key Performance Indicators for Cargo Ships (Levander, 2003)

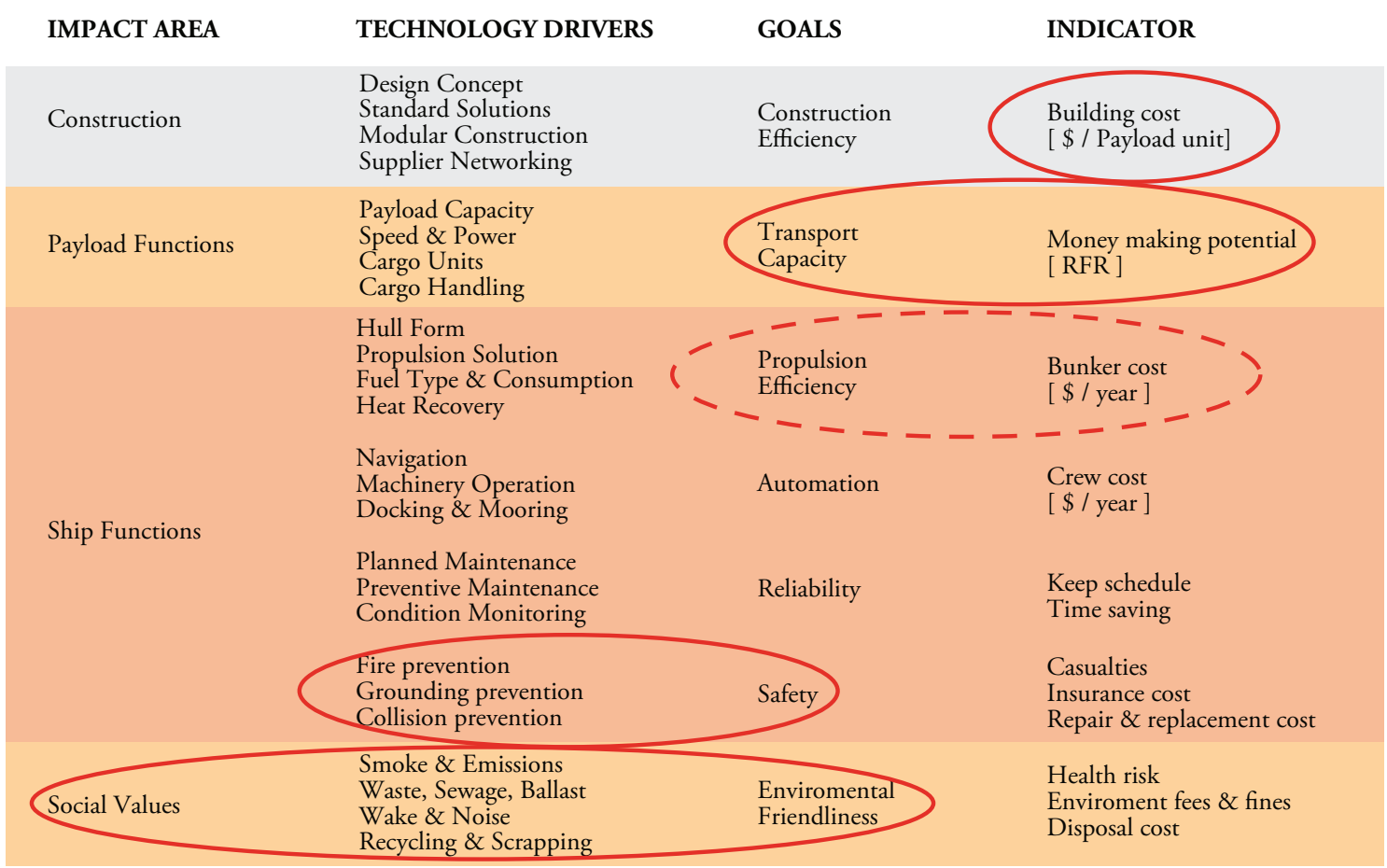

characterizing the design under optimization; for ship design, this includes the ship's main dimensions, unless specified by the ship owner's requirements (length, beam, side depth, draft) and may be extended to include the ship's hull form, arrangement of spaces and of (main) outfitting, of (main) structural elements and of (main) networking elements (piping, electrical, etc), depending on the availability of topological-geometry models relating the ship's design parameters to a generic ship model to be optimized.

- Input Data: This initially includes the traditional owner's specifications/ requirements, which for a merchant ship are the required cargo capacity (deadweight and payload), service speed, range, etc., and may be complemented by a variety of further data affecting ship design and its economic life, like financial data (profit expectations, interest rates), market conditions (demand and supply data), costs for major materials (steel and fuel), etc. The input data set may include, besides numerals of quantities, more general type of knowledge data, like drawings (of ship general arrangements) and qualitative information that needs to be properly translated for inclusion in a computer-aided optimization procedure.

- Output: It includes the entire set of design parameters (vector of design variables) for which the specified optimization criteria/merit functions obtain mathematically extreme values (minima or maxima); for multi-criteria optimization problems, optimal design solutions are on the so-called Pareto front and may be selected on the basis of tradeoffs by the decision maker/designer. For the exploration and final selection of Pareto design solutions, a variety of strategies and techniques may be employed.

In mathematical terms, the multi-objective optimization problem may be formulated as:

$$
\begin{aligned}
& \min \left[\mu_{1}(x), \mu_{2}(x), \ldots, \mu_{n}(x)\right]^{\mathrm{T}}, \\
& \text { subject to } g(x) \leq 0 \text { and } h(x)=0 \text { and } x_{l} \leq x \leq x_{u}
\end{aligned}
$$

where $\mu_{\mathrm{i}}$ is the $i$-th objective function, $g$ and $h$ are a set of inequality and equality constraints, respectively, and $x$ is the vector of optimization or vector of design variables. The solution to the above problem is a set of Pareto solutions, namely 
solutions for which improvement in one objective cannot be achieved without worsening of at least one other objective. Thus, instead of a unique solution, a multi-objective optimization problem has (theoretically) infinite solutions, namely the Pareto set of solutions.

The use of Multi-Objective Genetic Algorithms (MOGA), combined with gradient based search techniques in micro-scale exploration and with a utility functions technique for the design evaluation, is advanced in the present paper as a generic type optimization technique for generating and identifying optimized designs through effective exploration of the large-scale, nonlinear design space and a multitude of evaluation criteria occurring in ship design. Several applications of this generic, multi-objective ship design optimization approach by use of NTUA-SDL ${ }^{3}$ 's design software system, integrating the naval architectural software package $N A P A^{4}$, the optimization software modeFRONTIER ${ }^{5}$ and various application software

${ }^{3}$ National Technical University of Athens - Ship Design Laboratory, NTUA-SDL, http://www.naval.ntua.gr/sdl

${ }^{4}$ NAPA Oy (2005), NAPA software, http://www.NAPA.fi/

${ }^{5}$ E.STE.CO (2003), "modeFrontier software v.2.5.x", http://www. esteco.it/ tools, as necessary for the evaluation of stability, resistance, seakeeping etc. may be found in the listed references.

Two typical application examples of the introduced generic ship design optimization procedure of NTUA-SDL are presented and briefly commented in the following.

\section{Examples of Optimization of Merchant and Naval Ships}

\section{Multi-objective Optimization of Tanker Ships}

This application gives an overview of research studies undertaken at the Ship Design Laboratory of NTUA within the framework of the EU-funded project SAFEDOR (2005-2009) and, thereafter, in collaboration with Germanischer Lloyd (Papanikolaou et al., 2010). The studies introduce a risk-based parametric optimization of doublehull tankers to achieve innovative designs with increased cargo carrying capacity and improved environmental protection, while challenging

Fig. 4. Generic Procedure for the Ship Design Optimization Problem - NTUA-SDL

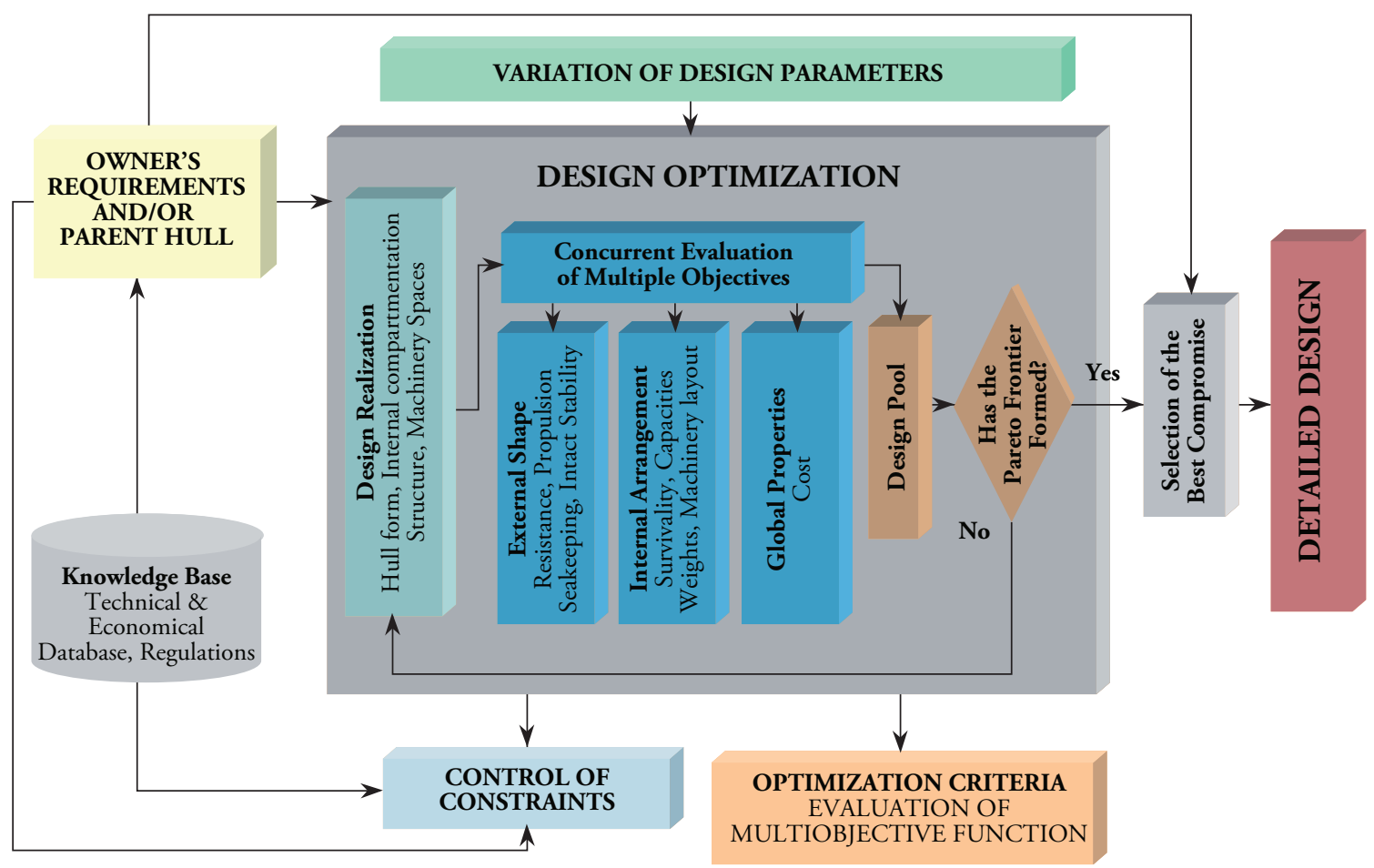


various constraints imposed by the latest MARPOL regulations (Papanikolaou, 2009c).

For the design concept development stage, a full parametric multi-objective design optimization platform by using Genetic Algorithms has been developed, taking into account probabilistic oiloutflow calculation methods for side and bottom damages. The resultant Pareto-optimal designs are evaluated from the point of view of oil outflow consequences, cargo capacity, design feasibility, ship maintainability and ballast water extent. Developed alternative designs dispose, compared to a standard double-hull design, increased cargo carrying capability and reduced structural weight, at a comparable or even slightly reduced risk for oil outflow; therefore, from the point of view of both economy and safety, they appear very promising compared to existing standard type doublehull designs. A preliminary economic analysis also showed that despite the anticipated slightly increased building cost, developed alternative designs are related to an appreciable decrease of unit transport cost, making them attractive to the shipping industry.

\section{Reference Design}

The, herein, optimized tanker vessel, code-named "Double Venture" is a double-hull construction tanker ship of AFRAMAX size also used in another EU-funded project POP\&C (2004-2007). Table 1 presents the basic characteristics of the vessel. A double-skin construction is arranged along the cargo length area, consisting of six (6) pairs of side and bottom tanks for use of water ballast (Fig. 5). Two slop tanks are also provided, aft wards of main cargo area. Cargo handling is by means of centrifugal pumps installed in a pump room, which is located forward of the machinery space. It is noted that the above referenced doublehull design disposes of an increased double side and bottom clearance of $2.5 \mathrm{~m}$, compared to the minimum $2.0 \mathrm{~m}$ required, according to MARPOL relevant requirements.

Fig 5. Sketch of Reference Vessel "Double Venture"

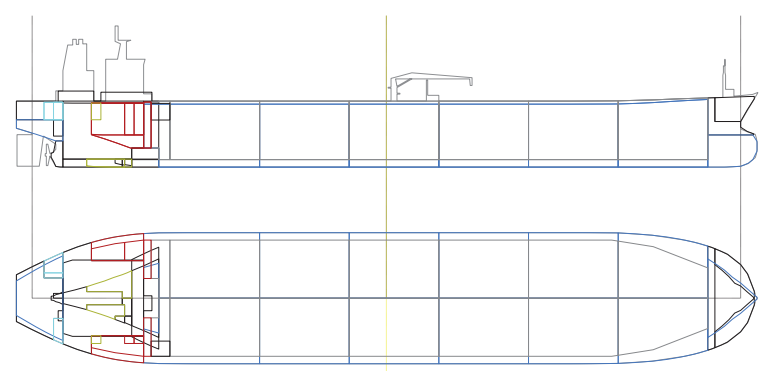

\section{Alternative Configurations}

Five different configurations were considered,

Table 1. Particulars of reference vessel "Double Venture"

\begin{tabular}{ll}
\hline Length, oa & $250.10 \mathrm{~m}$ \\
\hline Length, bp & $239.00 \mathrm{~m}$ \\
\hline Breadth, moulded & $44.00 \mathrm{~m}$ \\
\hline Depth, moulded (main deck) & $21.00 \mathrm{~m}$ \\
\hline Width of double skin sides & $2.50 \mathrm{~m}$ \\
\hline Width of double skin bottom & $2.50 \mathrm{~m}$ \\
\hline Draught scantling & $14.60 \mathrm{~m}$ \\
\hline Deadweight, scantling draught (comparable with & $109,800 \mathrm{dwt}$ \\
design proposed) & $($ cargo density $0.868 \mathrm{~T} / \mathrm{m} 3)$ \\
\hline Cargo capacity & $122,375 \mathrm{~m}^{3}+2,830 \mathrm{~m}^{3}(\mathrm{Slop}), 3,380 \mathrm{~m}^{3}$, \\
Liquid volume, heavy oil, diesel oil, & $260 \mathrm{~m}^{3}$ \\
Water ballast & $41,065 \mathrm{~m}^{3}+3,500 \mathrm{~m}^{3}(\mathrm{peaks})$ \\
\hline Classification & Lloyds Register \\
\hline Number of Cargo tanks & $12(6 x 2)$ plus 2 slop tanks \\
\hline Cargo Tanks block length & $181.44 \mathrm{~m}$ \\
\hline
\end{tabular}


with six or seven tanks in the longitudinal direction, two or three tanks in the transverse direction and flat or corrugated bulkheads. The five different combinations of compartmentation are summarized in Table 2. A total of 21,500 designs were examined in the present study. In Figs. 6 and 7, only the feasible designs are shown. The open circles correspond to dominated designs, while the full circles correspond to designs on the Pareto front. For comparison, the reference design is also included, marked by a full triangle. It should be noted that the steel weight of the reference vessel is not its actual weight as built, but the weight calculated by the POSEIDON software by Germanischer Lloyd, based on a corresponding structural design according to GL rules. This ensures full comparability with the generated optimal designs.

\section{Discussion of Results}

The five alternative configurations were selected to allow validating the characteristics of the reference design, as well as identifying possible improvements through analysis of the respective Pareto frontiers. Putting all Pareto frontiers into a single diagram provides a better insight of the relationships between design objectives, design parameters, and alternative configurations.

Fig. 6 clearly shows that the " $6 \times 3$ flat" Pareto designs dominate all the other designs. Furthermore, there are several Pareto designs with significantly better

Fig 6. Outflow vs. cargo volume - Pareto designs from different configurations

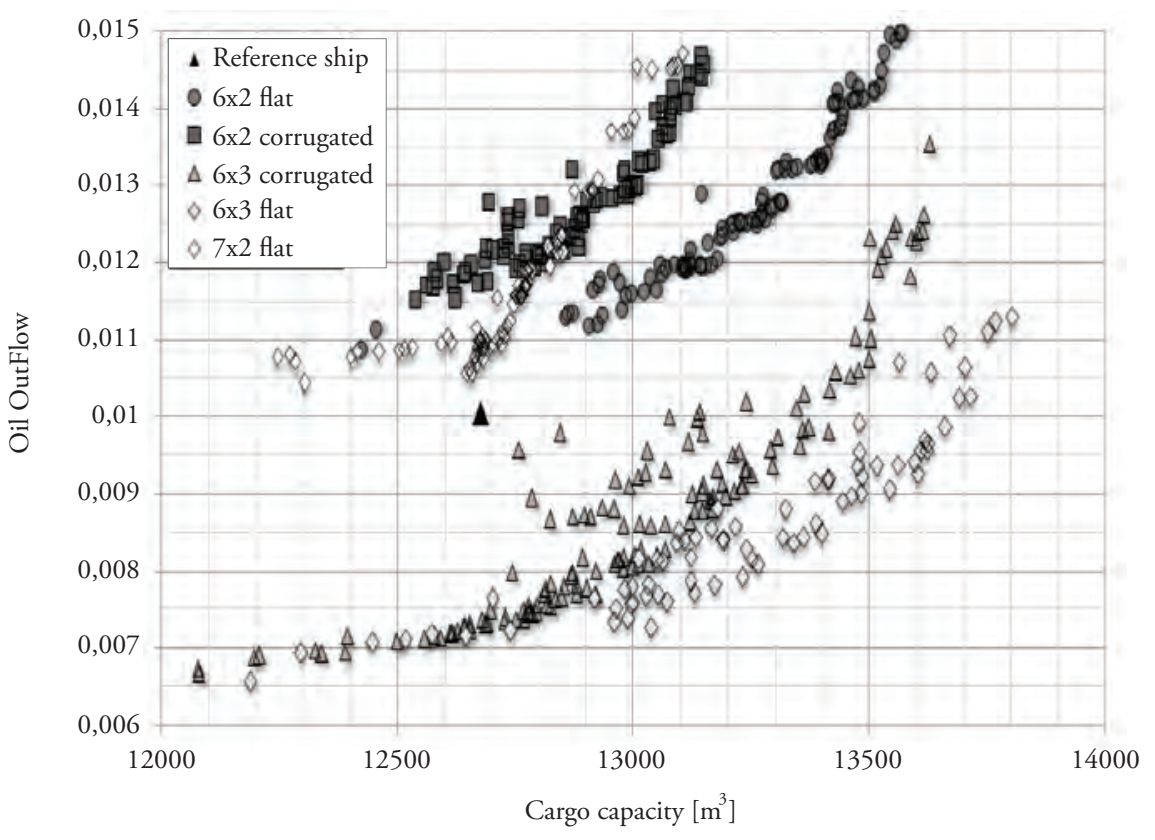

Table 2. Alternative compartmentation configurations

\begin{tabular}{lrlllr} 
& $\begin{array}{c}\text { Arrangement } \\
\text { of cargo } \\
\text { tanks }\end{array}$ & & \multicolumn{1}{c}{$\begin{array}{c}\text { Bulkhead } \\
\text { type }\end{array}$} & $\begin{array}{c}\text { Number of } \\
\text { designs }\end{array}$ \\
\cline { 1 - 2 } Configuration 1 & $6 \times 2$ & flat & 7287 \\
Configuration 2 & $6 \times 2$ & corrugated & 1738 \\
Configuration 3 & $6 \times 3$ & flat & 6147 \\
Configuration 4 & $6 \times 3$ & corrugated & 3270 \\
Configuration 5 & $7 \times 2$ & flat & 3043 \\
\hline
\end{tabular}


oil outflow (in terms of the MARPOL mean oil outflow index, which must be less than 0.015 for the reference AFRAMAX tanker) and cargo volume performance than the reference design.

As expected, Fig. 7 shows that for the same cargo volume, most generated " $6 \times 2$ flat" Pareto designs have less steel weight than all the other configurations, noting that the structural weight of both the generated Pareto designs and of the reference ship were calculated by the same model, namely here based on POSEIDON structural designs. The reference design is here again dominated by several " $6 \times 2$ flat" and " $6 \times 3$ flat" designs.

In Fig. 8, the " $6 \times 3$ flat" designs, as well as the "6x2 flat" designs dominate all other designs. The reference design is again clearly dominated by several " $6 \times 3$ flat" designs. At the same time, practically all " $6 \times 2$ flat" Pareto designs have less steel weight than the reference design at acceptable oil outflow performance.

Fig 7. Cargo volume vs. steel weight in cargo area - Pareto designs from different configurations

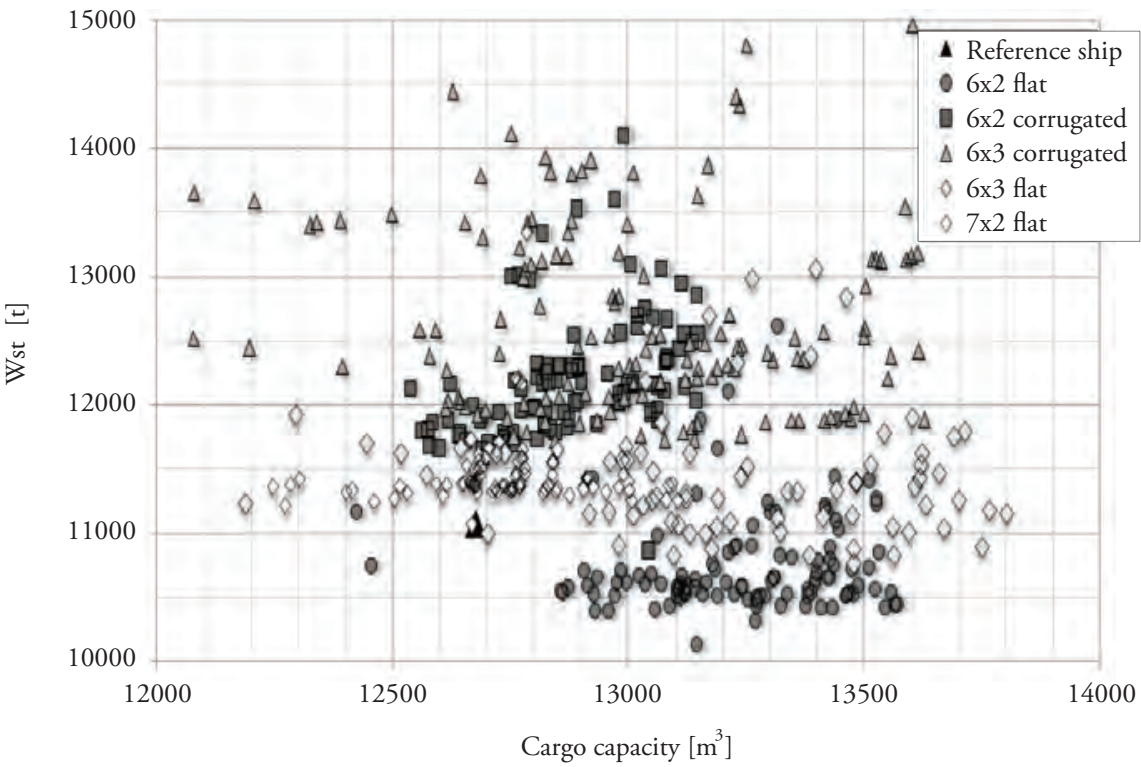

Fig 8. Outflow vs. steel weight in cargo area - Pareto designs from different configurations

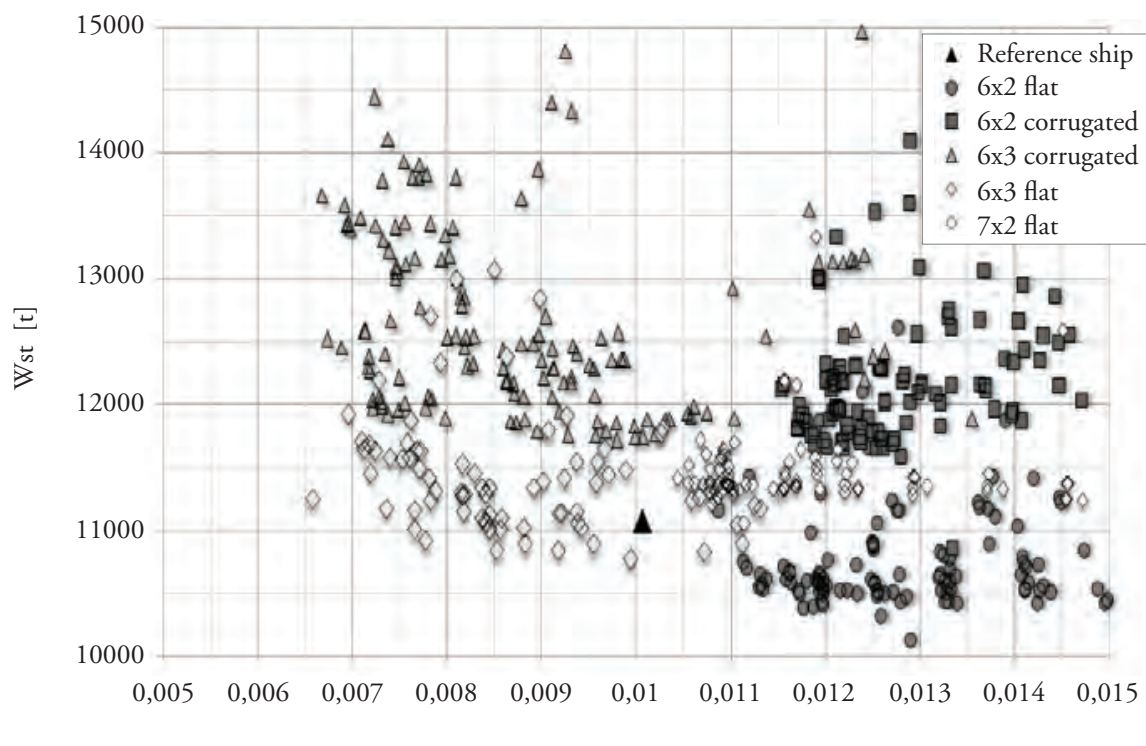

Oil OutFlow 
In addition to the above, the following observations can be made:

- None of the corrugated arrangements proves better than flat bulkhead designs. This does not mean that the corrugated geometries should be in general disregarded as alternative configurations. They have important advantages with respect to the ease of production and maintenance, which have not been considered in this study. Also, it should be noted that the flat bulkhead structural designs did not include some minor stiffeners, thus the comparison may be not entirely 'fair' in this respect.

- The "7x2 flat" arrangement performed poorly since the steel weight increases without any significant gains in the outflow or the capacity, respectively.

The reference design appears to be on the Pareto front of the " $6 \times 2$ flat" designs. It was already noted earlier that the reference design is a well-proven design in practice, which was optimized with respect to steel weight (by the yard designer), most likely by use of Finite Element Method (FEM). .

\section{Holistic Naval Ship Design}

\section{Introduction to Naval Ship Design}

From the system's point of view, a naval ship may be regarded as an integrated, self-propelled combat system. It may be requested to provide accommodation space for personnel of the size of a small village and be hosted within a large mobile structure that continuously operates in a hostile environment (physical and operational); thus, many challenges come in addition to those of a merchant ship design.

In recent years, the task of formulating clearer goals and setting tangible design specifications for naval ships has been significantly improved with the use of the 2010 International Naval Ship Code (INSC, 2010). The INSC is based on a similar philosophy like the Goal Based Standards (GBS), currently discussed for merchant ships at the International Maritime Organization (IMO). It addresses, however, specific naval ship features and methods of operation. The goals are represented at the top tiers of the framework, below which the detailed requirements which the ship has to meet in design, construction, and operational phase are placed. The structure of the NSC 2010 (ANEP 77 v.2, 2010) version of the code is explained in Figs. 9 and 10. The code offers an off-the-self safety and performance management system for navies that need to establish a system of self regulation.

Compared to a merchant ship, the complexity of designing a naval ship is further increased by the multitude of disciplines that need to be considered

Fig 8. Outflow vs. steel weight in cargo area - Pareto designs from different configurations

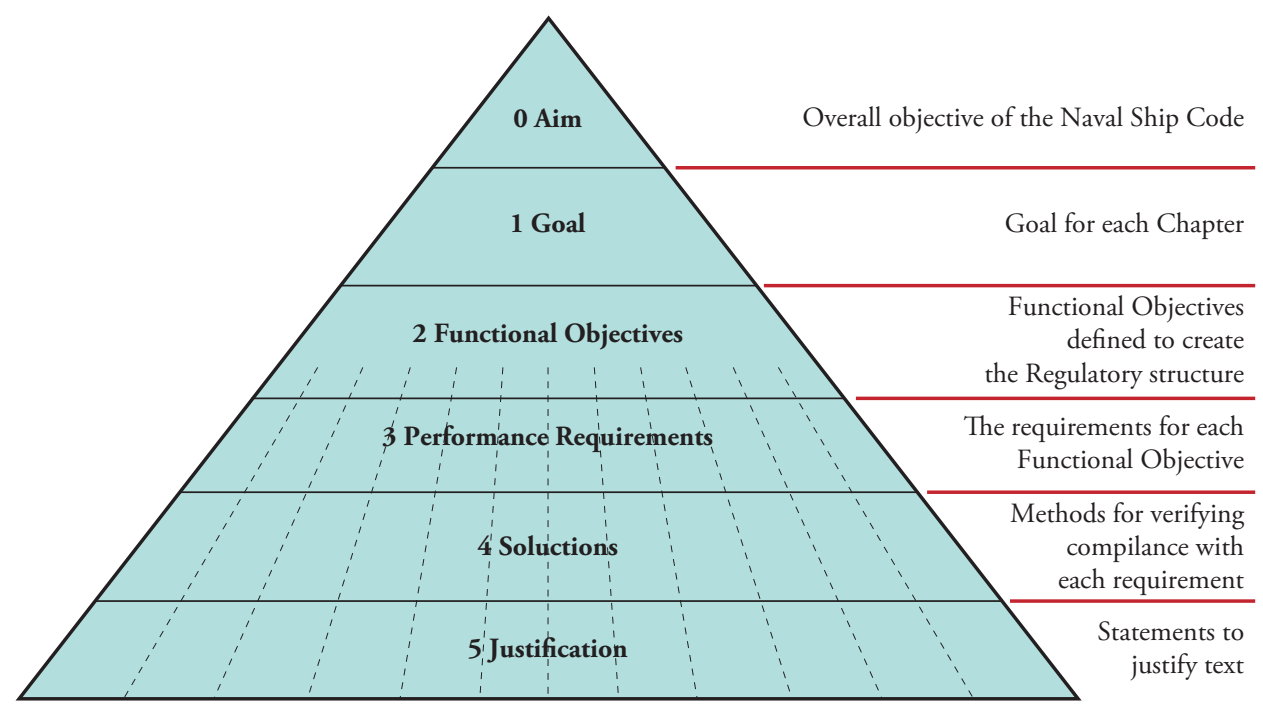


Fig 10. The GBS structure of the NSC (see RINA Warship Technology, 2011)

\begin{tabular}{|c|c|c|c|c|c|c|c|c|c|c|}
\hline Tier 0 & \multicolumn{10}{|c|}{ Aim Scope Introduction } \\
\hline $\begin{array}{l}\text { Tier } 1 \\
\text { Goal }\end{array}$ & Ch I & Ch II & Ch III & Ch IV & Ch V & Ch VI & Ch VII & Ch VIII & Ch IX & Ch X \\
\hline $\begin{array}{c}\text { Tier } 1 \\
\text { Functional } \\
\text { Objective }\end{array}$ & 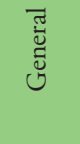 & 总 & 氞 & 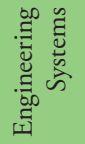 & 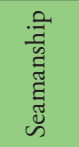 & 竧离 & 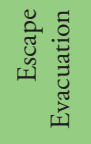 & 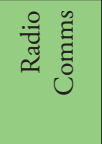 & 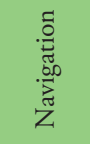 & 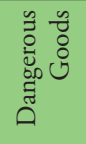 \\
\hline $\begin{array}{c}\text { Tier } 3 \\
\text { Performance } \\
\text { Requirements }\end{array}$ & $\begin{array}{l}\text { Reg } \\
0-21\end{array}$ & $\begin{array}{l}\text { Reg } \\
0-7\end{array}$ & $\begin{array}{l}\text { Reg } \\
0-7\end{array}$ & $\begin{array}{l}\text { Reg } \\
0-25\end{array}$ & Blank & $\begin{array}{l}\text { Reg } \\
0-13\end{array}$ & $\begin{array}{l}\text { Reg } \\
0-26\end{array}$ & $\begin{array}{l}\text { Reg } \\
0-1\end{array}$ & $\begin{array}{l}\text { Reg } \\
0-1\end{array}$ & $\begin{array}{l}\text { Reg } \\
0-1\end{array}$ \\
\hline $\begin{array}{c}\text { Tier } 4 \\
\text { Solutions }\end{array}$ & Code & Class & $\begin{array}{l}\text { National } \\
\text { standard }\end{array}$ & Class & $\begin{array}{l}\text { Ch V } \\
\text { Blank }\end{array}$ & Code & Code & SOLAS & SOLAS & IMDG \\
\hline
\end{tabular}

and integrated in the ship design process, as shown To enable major improvements in acquisition in Fig. 11. engineering design and analysis processes, many leading navies are working on developing and

Fig 11. Stakeholders disciplines of naval ship design (see Neu, 2000)

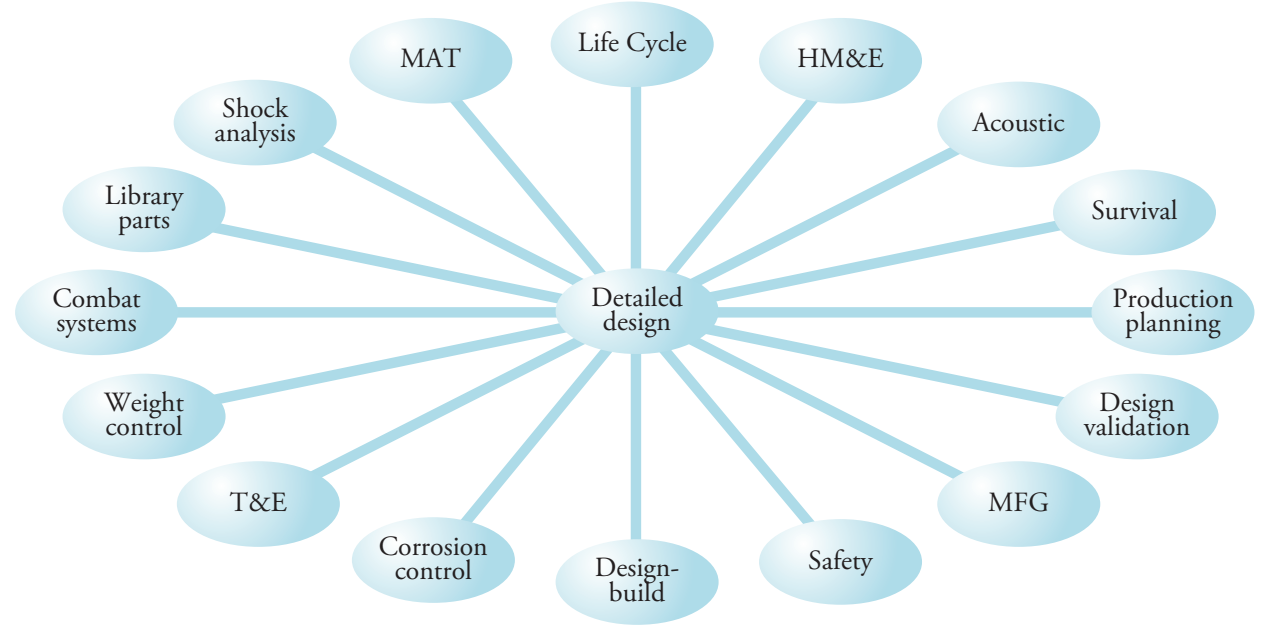

deploying scalable physics-based computational engineering software products aiming to replace empirical design based on historical data and experimental testing with physics-based computational design validated with experimental testing. This will allow the detection and resolution of any design flaws early in the design process before major schedule and budget commitments are made. Additionally, it will allow the innovation by the development of optimized designs for new concept and the integration of the various systems earlier in the acquisition process. The use of such a methodology will increase the acquisition program's flexibility and agility to respond to rapidly changing requirements (Hurwitz, 2010).

In that respect, Holistic Ship Design Optimization in naval ship design is achieved by the development of an integrated engineering software platform of tools that supports a reconfigurable ship design and acquisition process. This enables the designer to develop cost-effective ship designs on schedule 
Fig 12. Sample Integrated Toolset (see ISSC Committee v.5, 2009)

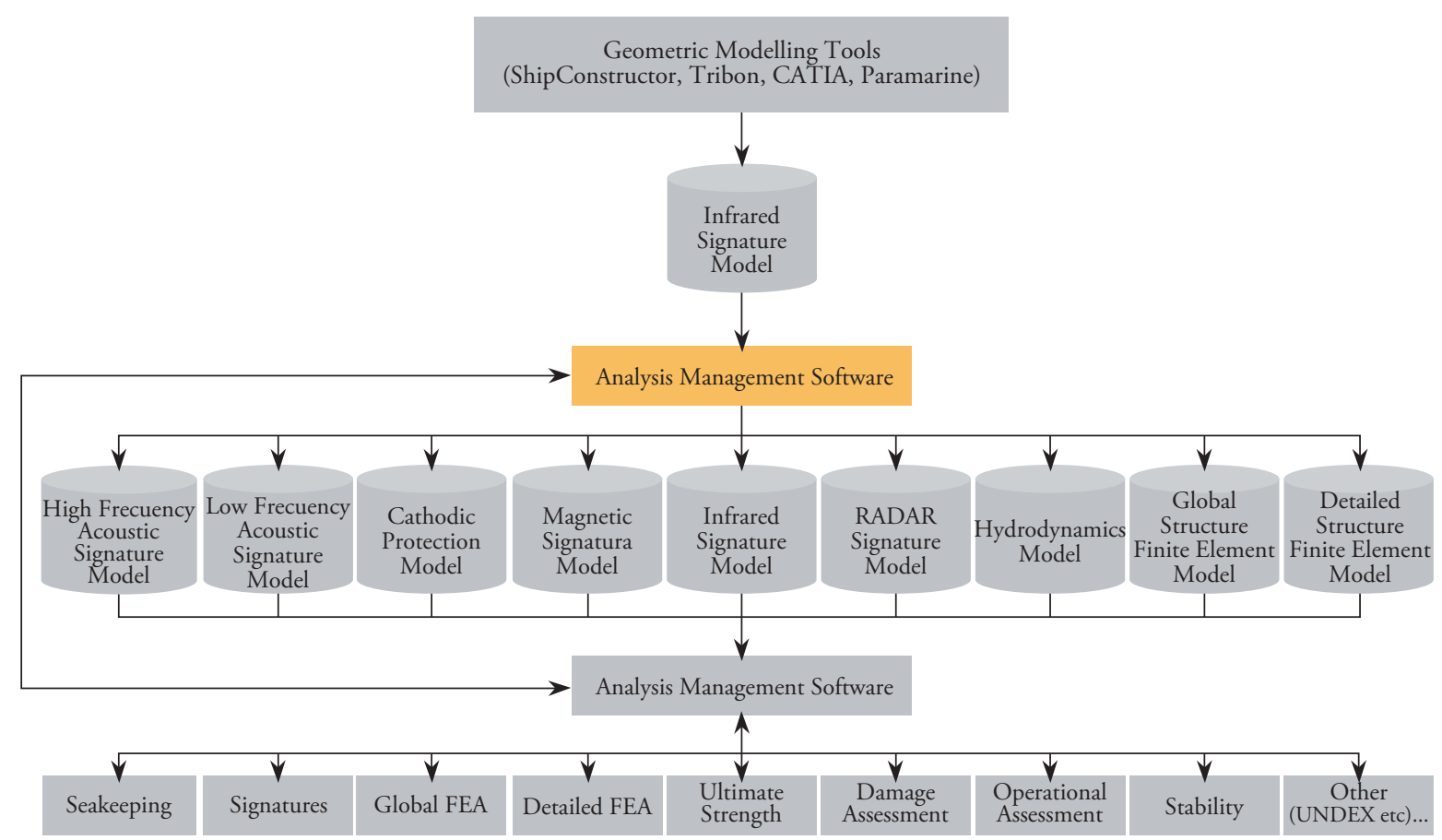

and within budget, able to perform as required and predicted. An example of such an integrated toolset is shown in Fig. 12.

At top level of Fig. 12, there are a number of geometric modeling tools (such as Tribon ${ }^{6}$, ShipConstructor ${ }^{7}$, CATIA $^{8}$, Paramarine ${ }^{9}$, NAPA $^{10}$ etc.). These software tools generate ship's geometry and related data which are then passed over to the appropriate Analysis Model Synthesizer that uses specialized Analysis Management Software such as (e.g.):

- Davis' ShipIR/NTCS ${ }^{11}$ for IR,

- IDS' Ship EDF for Radar Cross Section analysis (see Fig. 13),

- UCLand UoGs integrated PARAMARINESURFCON and maritimeEXODUS ${ }^{12}$ for design, simulation

\footnotetext{
$\overline{{ }^{6} \text { Now AVEVA Marine }} \mathrm{http}: / /$ www.aveva.com/products_services aveva_marine.php

${ }^{7} \mathrm{http}: / /$ www.shipconstructor.com/

${ }^{8} \mathrm{http}: / /$ www.3ds.com/solutions/shipbuilding/overview/

$9 \mathrm{http}: / /$ www.qinetic.com

${ }^{10} \mathrm{http}: / /$ www.napa.fi

${ }^{11} \mathrm{http}: / /$ www.wrdavis.com/NTCS_intro.html

$12 \mathrm{http} / / /$ fseg.gre.ac.uk/exodus
}

of evacuation and enhanced operational effectiveness (see Fig. 14).

The development and validation of such integrated tool platforms is a very demanding task; two well known software platforms, which are used and continuously further developed by two major navies, are:

- $\quad$ NAVSEAS (US) Leading Edge Architecture for Prototyping Systems (LEAPS) (Hurwitz, 2010)

- QinetiQ-GRC's PARAMARINE software in UK (http://www.qinetiq.com).

The Ship Design laboratory at NTUA has also been developing integrated approaches to naval ship design, namely by utilizing its generic ship design optimization procedure (outlined in Fig. 4) together with a set of specific design tools for naval ship design. These are:

- A naval ship design version of the Parametric Design Tool (PDT) developed

${ }_{13}$ http://www.idscompany.it/page.php?f=176\&id_v=2 
Fig 13. RCS warship analysis by Ship EDF (IDS Ingegneria dei Sistemi S.p.A. ${ }^{13}$ )

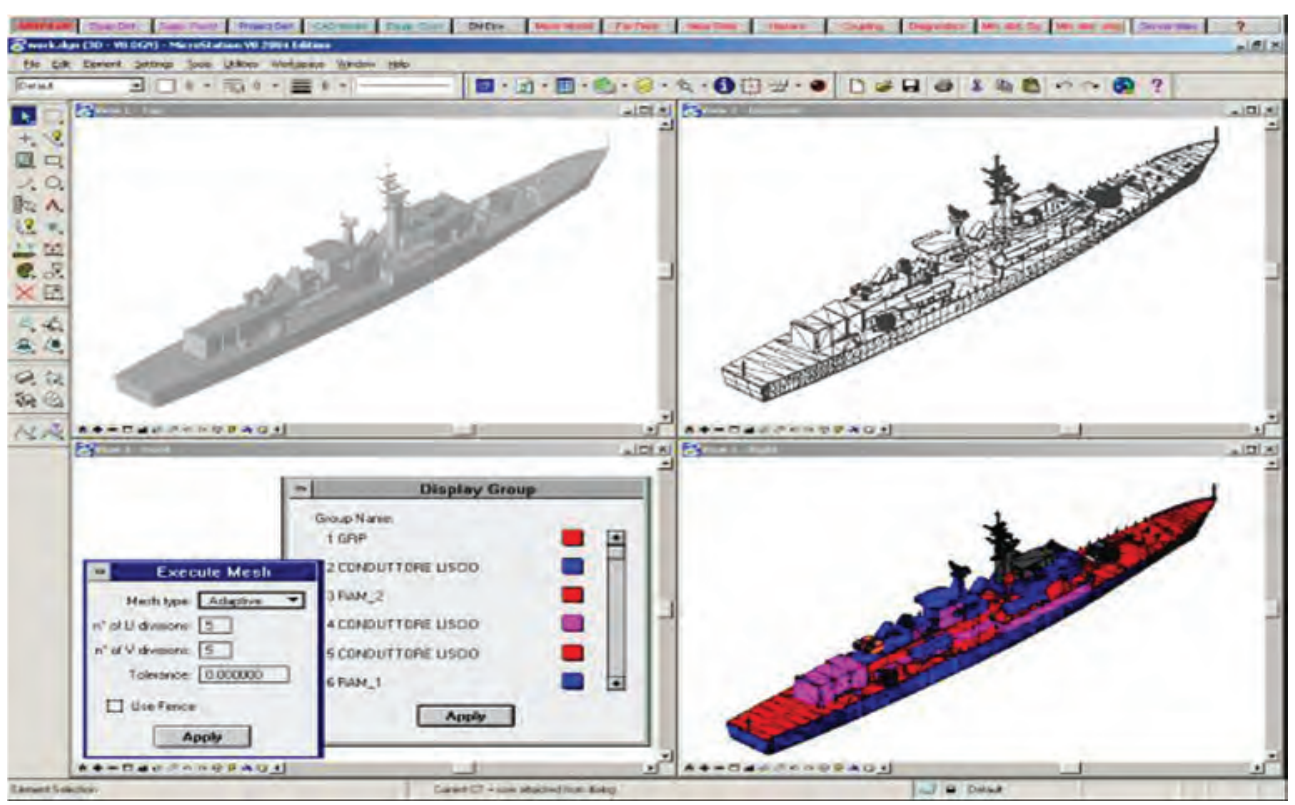

Fig 14. Personnel movement simulation results for RN Frigate (Andrews, 2009)

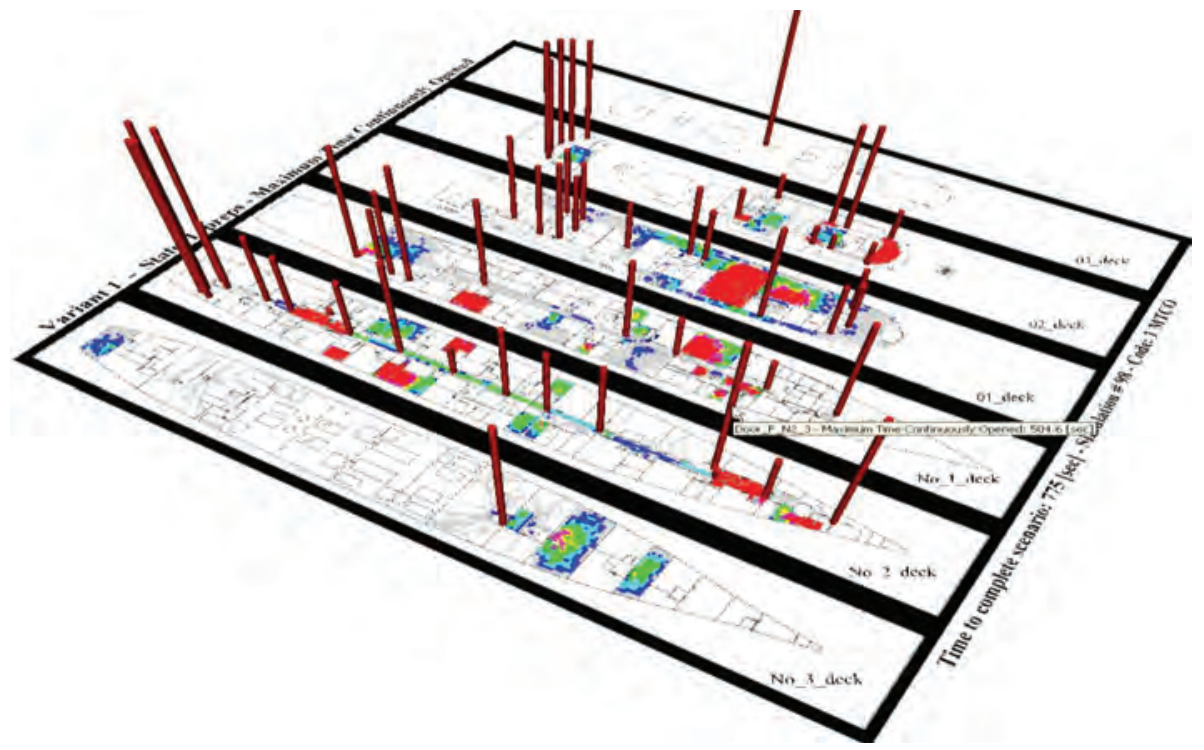

originally for the design of commercial ships (RoRo, tankers, bulkers, containerships) (Boulougouris and Papanikolaou, 2009) coupled with the general optimization software modeFRONTIER ${ }^{14}$ (see ES.TE. CO, 2003). This is used for the fast population of the design space with conceptual solutions that can be further investigated (Fig. 15).

- An advanced toolset integrating the wellknown ship design software package NAPA, modeFRONTIER and a number of external CAE tools such as NUMECA's $s^{15}$ Fine/Marine CFD code, NTUA-SDL's NEWDRIFT ${ }^{16}$ seakeeping (see Papanikolaou, 2001), Flowtech's 
Fig 15. NTUA-SDL Parametric Design Tool Design Space Global Exploitation

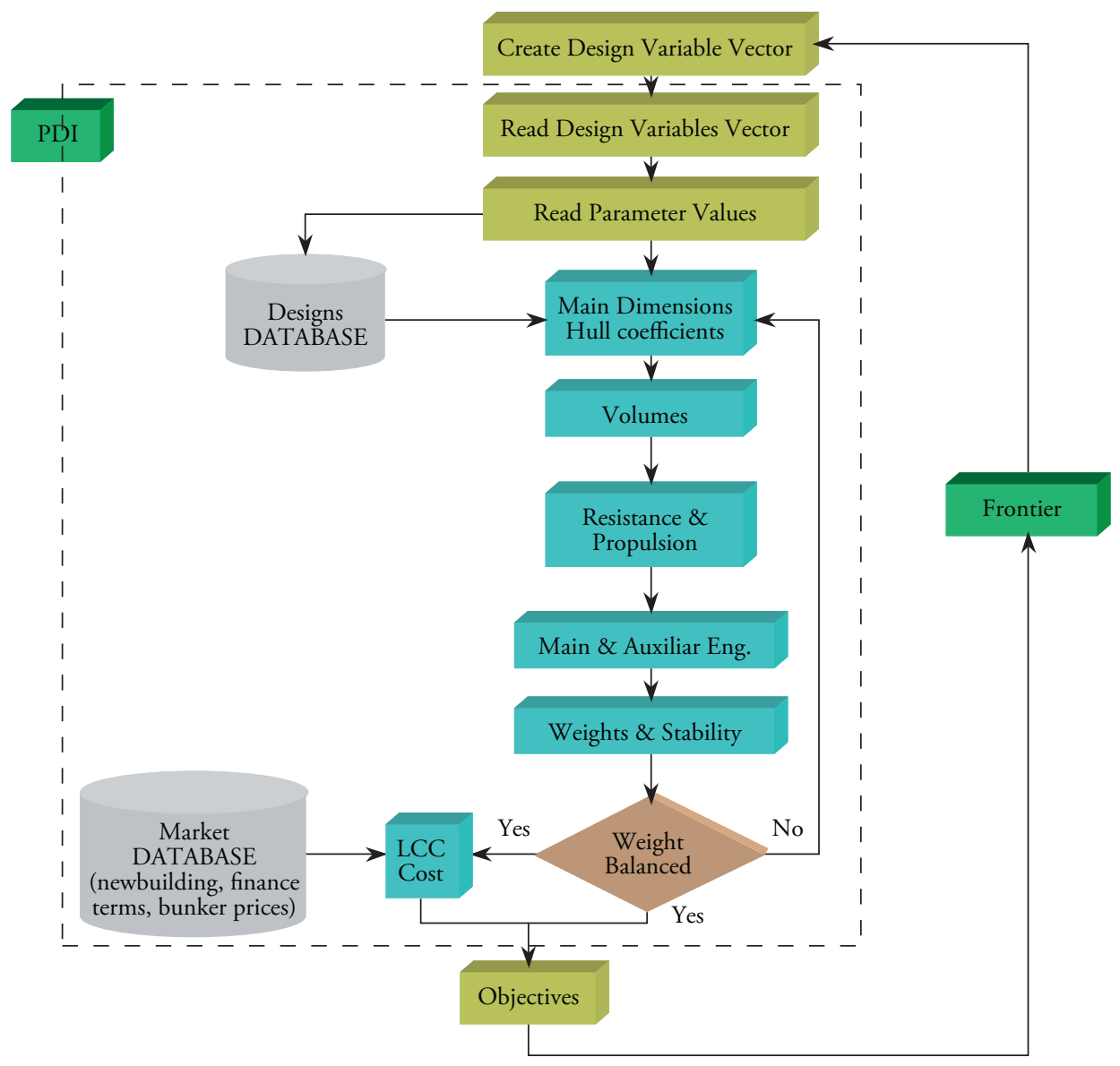

SHIPFLOW ${ }^{17}$ (see Larsson, 1990) and GL's POSEIDON $^{18}$ structural design software. In addition a number of tools have been programmed in NAPA macro-language using NAPA BASIC.

- Using a Parametric Design Tool (PDT) the designer has a computationally efficient tool for the parametric exploration of the design space and the identification of the feasible solutions areas. This is basically a global optimization step. After this step, the more sophisticated tools are introduced to perform the local, more in-depth optimization of the design, taking into account the full set of objectives and ranking the designs according to decision maker's preference.

17 http://www.flowtech.se

$18 \mathrm{http}: / / w w w . g l-g r o u p . c o m /$ poseidon2/
An example of application of this multi-objective optimization of a naval ship using genetic algorithms and including maximization of the survivability as one of the objectives may be found in the listed reference (Boulougouris and Papanikolaou, 2004).

\section{Summary and Conclusions}

The present paper provided a brief introduction to a holistic approach to ship design optimization, defined the generic ship design optimization problem, and demonstrated its solution by using advanced optimization techniques for the computer-aided generation, exploration, and selection of optimal designs. It discussed proposed methods on the basis of some typical ship design optimization problems of a tanker and naval ships 
related to multiple objectives, leading to improved and partly innovative design features with respect to ship economy, cargo carrying capacity, safety, survivability, comfort, required powering, environmental protection, or combat strength, as applicable.

It was shown that multi-objective mathematical optimization approaches are very valuable tools and greatly enhance the quality of ship design, even if applied to vessel concepts already optimized by traditional methods. The design developed and optimization methodology may be a useful tool for the designer in the preliminary design stage, facilitating the elaboration of a large number of design alternatives quickly and with little effort. The designer may explore this possibility to investigate the effect of crucial decisions on the vessel's operating performance before proceeding to the detailed design stage. The design methodology may also be effectively used in feasibility studies, providing assistance for the determination on a rational basis of the most suitable vessel size, transport capacity, speed, and other operating characteristics for a selected service. The integration of the parametric ship design application with a multi-objective optimization software facilitates the design space exploration in a rational and efficient way, enabling the identification of favorable and unfavorable areas of the design variables and ultimately for the determination of the optimal designs located on the Pareto Frontier (in case of multi-criteria optimization). Furthermore, once the optimum design has been selected, its detailed NAPA model including (but not limited to) the hull-form and the watertight subdivision is readily available for further elaboration and detailed design work, considerably reducing related effort.

A final comment on the way ahead: though the generic solution approach to the holistic ship design problem appears well established, it remains for researchers to develop and integrate a long list of application algorithms and related software, addressing the great variety of ship design for life cycle. This is a long-term task of decades, requiring profound skills and understanding of the physics and design of ships, a domain requiring properly trained naval architects and scientists from related disciplines.

\section{Acknowledgements}

The author likes to thank his associate, Dr. E. Boulougouris, Assoc. Prof. Dep. of Naval Architecture, TEI Athens, for his longstanding contributions to the herein presented work and particularly to the naval ship design section of the present paper.

\section{References}

ANDREWS D., PAWLING R., The Impact of Simulation on Preliminary Ship Design, $10^{\text {th }}$ Int. Marine Design Conference (IMDC'09), Vol.1, Trondheim, May 2009.

ANDREWS, D. (COODINATOR), PAPANIKOLAOU, A., ERICHSEN, S. AND VASUDEVAN, S., State of the art report on design methodology, Proc. $10^{\text {th }}$ Int. Marine Design Conference-IMDC09, Trondheim, May 2009.

BOULOUGOURIS E, PAPANIKOLAOU A., Hull Form Optimization of a High-Speed Wave Piercing Monohull, Proc. $9^{\text {th }}$ Int. Marine Design Conference-IMDC06, Ann ArborMichigan, May 2006.

BOULOUGOURIS, E., PAPANIKOLAOU, A., Optimisation of the Survivability of Naval Ships by Genetic Algorithms, Proc. $3^{\text {rd }}$ Int. Conference on Computer and IT Applications in the Maritime Industries (COMPIT'04), Siguënza, Spain, May 2004

BOULOUGOURIS E. K., PAPANIKOLAOU A. AND ZARAPHONITIS G., Optimisation of Arrangements of Ro-Ro Passenger Ships with Genetic Algorithms. Ship Technology Research, Verlag Heinrich Söding, 51:3, pags. 99-105, 2004. 
BOULOUGOURIS, E., PAPANIKOLAOU, A., Energy Efficiency Parametric Design Tool in the frame of Holistic Ship Design Optimization, $10^{\text {th }}$ Int. Marine Design Conference (IMDC'09), Vol. 1, Trondheim, May 2009.

BRETT PO, BOULOUGOURIS E, HORGEN R, KONOVESSIS D, OESTVIK I, MERMIRIS G, PAPANIKOLAOU A, VASSALOS D. A Methodology for the Logistics-Based Ship Design", Proc. $9^{\text {th }}$ Int. Marine Design Conference-IMDC06, Ann Arbor-Michigan, May 2006.

FLOWMART (2000-2003), Fast Low Wash Maritime Transportation. EU funded project, 5th Framework Programme, Contract number G3RD-CT 1999-00013.

GKOHARI, D., PAPANIKOLAOU, A., Optimization of Ship design within an Integrated Multimodal Transport System, Journal of Ship Production-SNAME, Vol. 26, 1, pp. 47-59, Feb. 2010, ISBN 8756-1417, ISSN: 1542-0469.

HURWITZ, M. , Plans and Status of the CREATE-SHIPS Project: Enabling Required Naval Warship Performance Throughout the Acquisition Lifecycle, $13^{\text {th }}$ Annual Systems Engineering Conference, San Diego, CA, 27 October 2010.

INTERNATIONAL MARITIME ORGANIZATION (IMO), Prevention of Air Pollution from Ships. Report of the Working Group on Greenhouse Gas Emissions from Ships. MEPC 58/ WP. 8, October 2008.

INTERNATIONAL NAVAL SAFETY ASSOCIATION (INSA), Naval Ship Code, NATO-ANEP-77 Edition 2, July 2010, http:// www.navalshipcode.org/.

ISSC 09-COMMITTEE V.5 (2009), Naval Ship Design, $17^{\text {th }}$ Int. Ship And Offshore Structures Congress (ISSC 09), 16-21 August 2009, Seoul, Korea.
LEVANDER, K., Innovative Ship Design - Can innovative ships be designed in a methodological way, Proc. $8^{\text {th }}$ Int. Marine Design Conference -IMDC03, Athens, May 2003.

LOGBASED (2004-2007), Logistics Based Design, EU funded project, $6^{\text {th }}$ Framework Programme, Contract number TST3CT-2003-001708.

NEU W.L. HUGHES O. MASON W.H. NI S. CHEN Y. GANESAN V. LIN Z. TUMMA S., A Prototype Tool for Multidisciplinary Design Optimization of Ships, Proc. $9^{\text {th }}$ Congress of the Int. Maritime Association of the Mediterranean (IMAM'00), April 2000, Naples, Italy.

NOWACKI, H., Developments in Marine Design Methodology: Roots, Results and Future, Proc. $10^{\text {th }}$ International Marine Design Conference, IMDC09, Trondheim, May 2009.

PAPANIKOLAOU A (ed). Risk-based Ship Design - Methods, Tools and Applications. SPRINGER Publishers, ISBN 987-3-54089041-6, 2009c.

PAPANIKOLAOU A. (coordinator), Andersen P, Kristensen HO, Levander K, Riska K, Singer D, Vassalos D. State of the Art Design for X. Proc. 10th Int. Marine Design ConferenceIMDC09, Trondheim, May 2009a.

PAPANIKOLAOU, A.; ZARAPHONITIS G., Computer Program NEWDRIFT v.7, Internal Report, NTUA, Greece, 2001.

PAPANIKOLAOU, A., Holistic ship design optimization. Journal Computer-Aided Design (2009), doi:10.1016/j.cad.2009.07.002, 2009b.

PAPANIKOLAOU, A., "Computer-Aided Preliminary Design of a High-Speed SWATH Passenger/Car Ferry," Proc. of the $4^{\text {th }}$ IMSDC '91 Conference, Kobe, May 1991.

PAPANIKOLAOU, A., P. KAKLIS, C. 
KOSKINAS AND D. SPANOS, Safety. EU-funded project, $6^{\text {th }}$ Framework "Hydrodynamic Optimisation of Fast Programme, contract TIP4-CT-2005-516278, Displacement Catamarans," Proc. 2l $\mathrm{l}^{\text {st }}$ Int. Symposium of Naval Hydrodynamics, ONR' 96, Trondheim, June 1996.

PAPANIKOLAOU, A., ZARAPHONITIS, G., BOULOUGOURIS, E., LANGBECKER, U., MATHO, S., SAMES, P., Multi-Objective Optimization of Oil Tanker Design, Journal Marine Science and Technology, Springer Verlag, Tokyo, 2010.

POP\&C (2004-2007), Pollution Prevention and Control, EU funded project, $6^{\text {th }}$ Framework Programme, Contract No. FP6-PLT-506193.

RINA WARSHIP TECHNOLOGY, (2011), New safety standard will continue to evolve, The Royal Institute of Naval Architects, pp. 26-28, January 2011.

SAFEDOR (2005-2009) Integrated Project on Design, Operation and Regulation for

SKOUPAS, S., ZARAPHONITIS, G., PAPANIKOLAOU, A., Parametric Design and Optimization of High-Speed, twinHull Ro-Ro Passenger Vessels, Proc. 10 ${ }^{\text {th }}$ International Marine Design Conference, IMDC09, Trondheim, May 2009.

VRSHIP-ROPAX2000 (2001-2005), A Virtual Environment for Life-Cycle Design of Ship Systems, EU funded project, $5^{\text {th }}$ Framework Programme, Contract Number G3RDCT-2001-00506.

ZARAPHONITIS G, PAPANIKOLAOU A, MOURKOYIANNIS D. Hull Form Optimization of High Speed Vessels with Respect to Wash and Powering. Proc. $8^{\text {th }}$ Int. Marine Design Conference-IMDC03, Athens, May 2003. 